\title{
Valorization of Lignin as a Sustainable Component of Structural Materials and Composites: Advances from 2011 to 2019
}

\author{
Menisha S. Karunarathna and Rhett C. Smith * \\ Department of Chemistry, Clemson University, Clemson, SC 29634, USA; mkaruna@clemson.edu \\ * Correspondence: rhett@clemson.edu
}

Received: 13 December 2019; Accepted: 15 January 2020; Published: 20 January 2020

\begin{abstract}
Lignin is the most abundant aromatic biopolymer and is the sustainable feedstock most likely to supplant petroleum-derived aromatics and downstream products. Rich in functional groups, lignin is largely peerless in its potential for chemical modification towards attaining target properties. Lignin's crosslinked network structure can be exploited in composites to endow them with remarkable strength, as exemplified in timber and other structural elements of plants. Yet lignin may also be depolymerized, modified, or blended with other polymers. This review focuses on substituting petrochemicals with lignin derivatives, with a particular focus on applications more significant in terms of potential commercialization volume, including polyurethane, phenol-formaldehyde resins, lignin-based carbon fibers, and emergent melt-processable waste-derived materials. This review will illuminate advances from the last eight years in the prospective utilization of such lignin-derived products in a range of application such as adhesives, plastics, automotive components, construction materials, and composites. Particular technical issues associated with lignin processing and emerging alternatives for future developments are discussed.
\end{abstract}

Keywords: lignin; polyurethane; phenol formaldehyde resins; sulfur; carbon fibers

\section{Introduction}

The word "lignin" is derived from the Latin word "lignum", meaning "wood" [1]. It is in wood that lignin may be most familiar to the layperson. A sample of wood contains light-colored material and a darker material that gives wood its characteristic grain pattern. The darker material is primarily lignin. The structural parts of most plants are likewise composed of lignin intermingled with cellulose and hemicellulose. On a cellular level, it is the plant cell middle lamella and the secondary cell wall that mainly contain lignin, accounting for $15-35 \%$ of a plant's dry weight [2,3]. Chemically, lignin is a three-dimensional structure that combines phenyl propane units through both ether and alkyl linkages (Figure 1). The rigidity afforded by the 3D structural array of primarily aromatic subunits in lignin lays the basic foundation to provide structural integrity to plant or timber-built structures. Despite the well-known role of lignin as a structural element of plants, efforts to valorize lignin as a component of synthetic structural polymers and composites for commercial applications have not yet reached their presumed potential. One reason for the slow development of this area may be that, in contrast to feedstock for most commercial products, lignin is not a material having a discrete, well-defined structure, both because of the complexity and because the particular structure of lignin differs depending on the plant species, extraction method and even growing conditions [4]. Despite the challenges involved, developing strategies to harness lignin for value-added applications is imperative for the success of the burgeoning green economy. The average annual disposal of lignin in the agricultural industry is around $50 \mathrm{Mt}$, while another $6 \mathrm{Mt}$ of waste lignin/chlorolignin results 
from paper/pulp production [5], and current projections suggest that lignin production will exceed $120 \mathrm{Mt}$ by 2022 [2]. Lignin also comprises $15-35 \mathrm{wt} . \%$ of the $>9$ billion tons/y of lignocellulosic waste from agriculture [6]. Only $2 \%$ of waste lignin is used to synthesize chemical compounds like vanillin and polyol compounds, while the rest of the lignin is burned as a low-cost, albeit low fuel value $(25.6 \mathrm{MJ} / \mathrm{kg})$ [7]. As momentum builds towards cellulosic ethanol as a primary fuel source, even more lignin will be left behind after removal of cellulose from the composite biomass for its conversion to cellulosic ethanol.

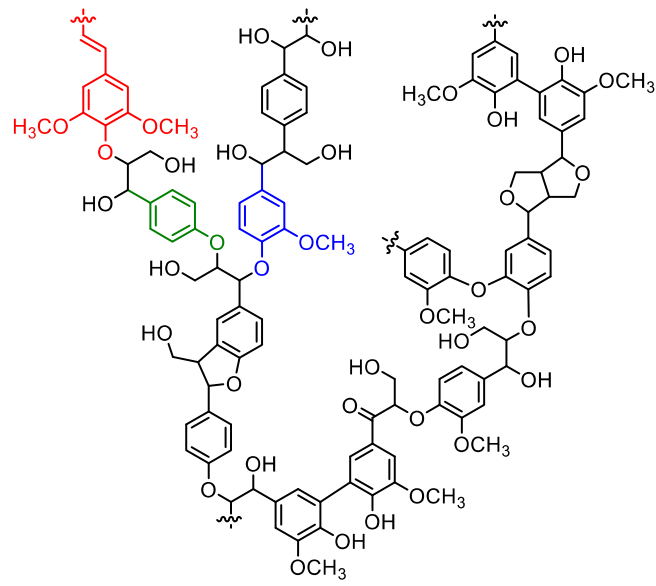

Figure 1. Schematic representation for the macromolecular structure of lignin. (Major monolignol units are colored as sinapyl alcohol-red, guaiacyl alcohol-blue, $p$-coumaryl alcohol-green).

The current review focuses on significant advances in materials derived from lignin with specific potential to replace petroleum-based chemicals. The commendable success in generating polyols for polyurethane and phenol-formaldehyde industries, replacing high-cost petroleum-based precursor materials in carbon fibers, and the utilization of lignin in extending sustainable sulfur cements are particular topics highlighted herein. In addition to these approaches, the challenges and the impact on each application for replacing traditional commercial materials are discussed. Remarks on future strides toward a sustainable world and insight on possible future research directions and challenges for the field are provided.

\section{Lignin Derivatives for Polyurethane Synthesis}

Polyurethanes are widely used plastics, traditionally prepared from petroleum-derived polyols and isocyanates. Polyurethanes have shown tremendous property tunability depending on the particular formulation, resulting in a commensurately wide range of applications. Polyurethane products can take the form of adhesives, sealants, rigid or flexible foams, and coatings [8]. Half of the polyol market in the United States is directed to polyurethane production [9]. The high abundance of phenolic and aliphatic-OH groups in lignin makes it an obvious candidate to replace petroleum-derived polyols in polyurethane production (Table 1). The most direct route to lignin-polyurethanes that has been explored is to replace polyols with lignin particles (Scheme 1) [10]. In these studies, careful evaluation of how properties are related to hydroxyl: isocyanide ratio, lignin solubility in reaction media, and lignin particle dispersion must be undertaken. Although lignin is comprised of a high number of phenolic moieties, isocyanate groups exhibit moderate selectively for reaction with aliphatic $\mathrm{OH}$ groups over phenolic groups. Furthermore, due to the prevalence of bulky fragments in lignin, isocyanate groups do not react with all of the $\mathrm{OH}$ groups of lignin. For these reasons, the greatest success has been observed when the $\mathrm{NCO} / \mathrm{OH}$ ratio is high, generally $\geq 1.0 \mathrm{~mol} \mathrm{NCO} / \mathrm{mol}$ hydroxyl [11]. Another strategy to increase coupling to lignin particles is to modify lignin to increase its solubility and to increase the number of aliphatic $\mathrm{OH}$ groups available for reaction. To facilitate discussion, products are classified as modified and unmodified lignin-based polyurethanes. 
Table 1. Summary of Lignin Polyurethanes.

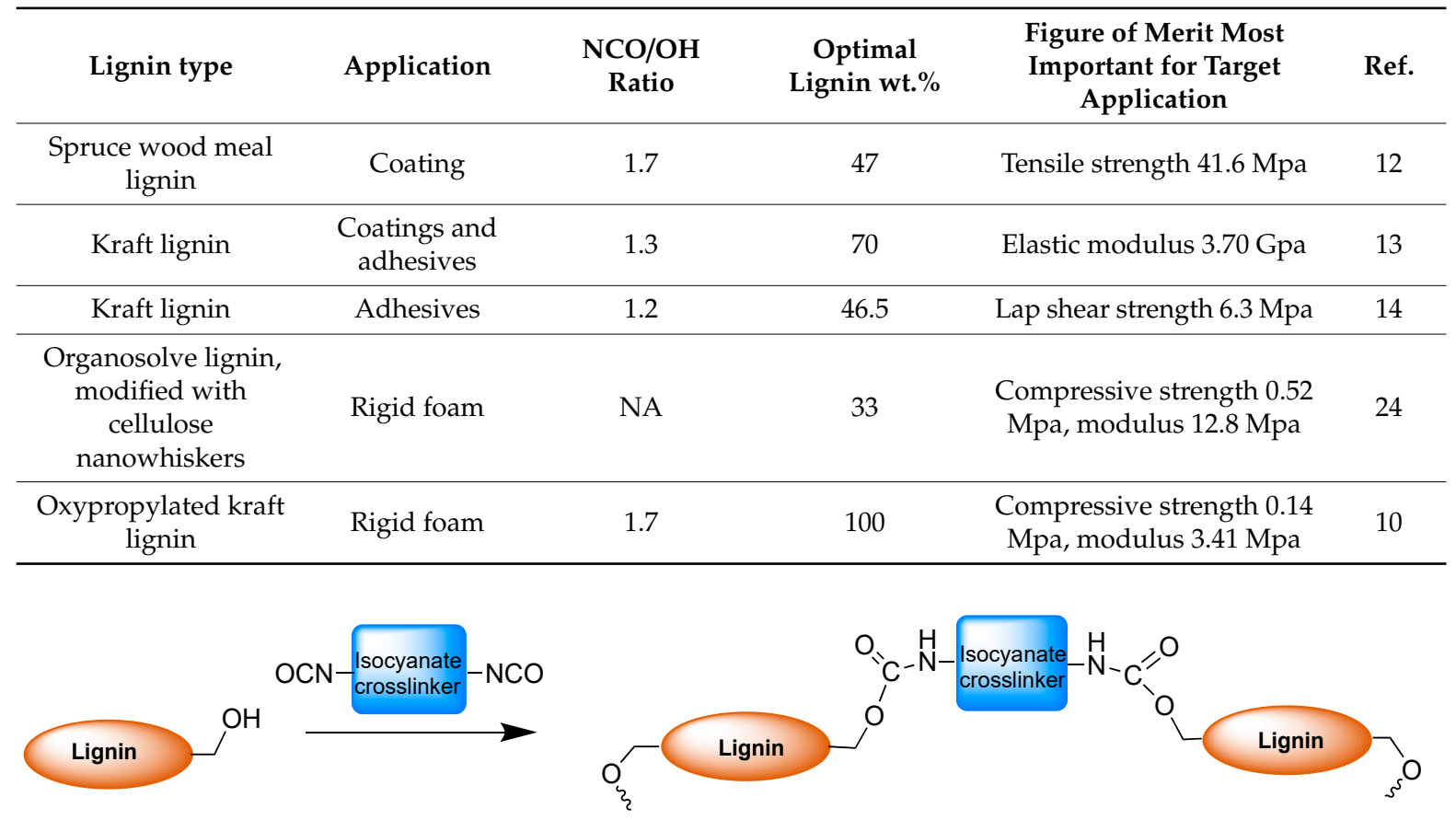

Scheme 1. Prototype reaction showing urethane bridge formation with lignin and isocyanate crosslinkers.

\subsection{Polyurethanes Prepared from Unmodified Lignin}

In a recent report by $\mathrm{Lu}$ and coworkers [12], spruce wood meal was pretreated by boiling in 1,4-butanediol with $\mathrm{HCl}$. The pretreated lignin then reacted with methylene diphenyl diisocyanate, (MDI) as the crosslinker in dioxane. This formulation allowed casting of a monolithic polyurethane film. A maximum tensile strength of $41.6 \mathrm{MPa}$ was achieved at a $\mathrm{NCO}: \mathrm{OH}$ ratio of 1.7 , equating to an impressive $47 \%$ lignin by mass. These polyurethanes exhibit properties competitive with traditional formulations used in coatings requiring high performance in hardness and solvent resistance [12].

Griffini and coworkers [13] demonstrated that lignin polyurethanes can also have high performance metrics for wood and glass adhesives. These adhesives were prepared from unmodified kraft lignin, which is soluble in 2-methyltetrahydrofuran (MeTHF). When kraft lignin was reacted in MeTHF with toluene diisocyanate (TDI) as the crosslinker, a maximum adhesive strength (3.70 GPa) was achieved with a NCO/OH ratio of 1.3 and contained $70 \mathrm{wt} . \%$ lignin [13]. Another approach to lignin polyurethane adhesives allows reaction of technical-grade kraft lignin with MDI in THF [11]. These adhesives displayed reasonable performance for binding wood surfaces, with a maximum lap shear strength of $6.3 \mathrm{MPa}$ achieved at a $1.2 \mathrm{NCO} / \mathrm{OH}$ ratio.

\subsection{Polyurethanes Prepared from Modified Lignin}

The mechanical properties of traditional polyurethane resins are mainly controlled by the degree of crosslinking with isocyanate groups. Recent efforts have centered on modifying lignin in ways hypothesized to increase crosslink density. Demethylation of methyl ethers is one such strategy that can increase the number of $\mathrm{OH}$ groups available for crosslinking. The 5-methoxy group in syringyl alcohol subunits, for example, is conveniently converted to a hydroxyl group by exposure of the lignin to $\mathrm{SO} 2$ or $\mathrm{HBr}$. The SO2-mediated route leads to an impressive $54 \%$ increase in hydroxyl groups [14], while the HBr-mediated method increased hydroxyl content by $28 \%$ [15]. In this case, however, the significant increase in crosslinkable sites led to films that were too brittle for practical applications. The brittleness can be controlled to some extent by the addition of polyethylene glycol to tune the crystallinity. In contrast with some previous lignin polyurethanes comprising up to $70 \mathrm{wt} . \%$ lignin, however, the more-crosslinked material could only be formulated with up to $17 \mathrm{wt} . \%$ lignin in this case. 
Some of the technical constraints of using lignin in its crosslinked macromolecular form can be overcome by prior liquefaction. Oxypropylation has been recognized as an especially productive method for the liquefaction of lignin [16,17]. The lower nucleophilicity of phenols with respect to aliphatic alcohols diminish their reactivity towards isocyanates. Consequently, the phenolic moieties in lignin do not efficiently react with isocyanate monomers. Oxypropylation was used as an effective effort to enhance the reactivity, as lignin is reacted with propylene oxide to form aliphatic ligno-polyol derivatives and polypropylene oxide (Scheme 2) [18]. Introducing multiple ether units as chain extenders also served to liquify the solid lignin $\left(\mathrm{Tg}=-75^{\circ} \mathrm{C}\right)$, minimizing the technical issues in processability [19-22]. In most formulations for PU (polyurethane) foams, the resultant polypropylene oxide homopolymer is separated from the mixture before reacting with isocyanate monomers. Pavier and Gandini devised an efficient method to remove the homopolymer via extraction with hot hexane followed by vacuum drying [19].

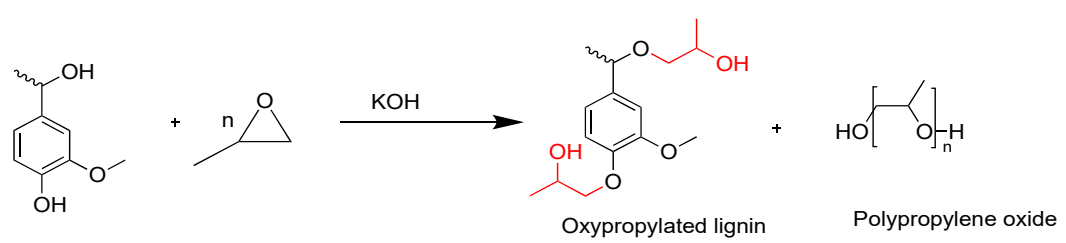

Scheme 2. Schematic representation for the oxypropylation of lignin.

In the quest to access lignin polyurethanes for rigid foam applications, success has come from employing oxypropylated ethanol organosolve lignin, modified with cellulose nanowhiskers [23]. This modified lignin was reacted with MDI utilizing dimethylcyclohexaneamine and by employing a Mannich base as a catalyst to improve reactivity. Incorporating just $5 \mathrm{wt} . \%$ of cellulose nanowhiskers into the foam led to a remarkable $260 \%$ increase in compressive strength, while adding an additional 1-5 wt.\% cellulose fibers did not lead to any additional improvements. The maximal compressive strength was obtained with $33 \mathrm{wt} . \%$ lignin incorporation, while attempts to increase this loading led to a precipitous drop in compressive strength. Follow-up efforts have achieved an additional $30 \%$ increase in compressive strengths when the lignin was modified with 1,4 butanediol chain extenders. The improved strength likely results from better reactivity that should result from less steric encumbrance about hydroxyl sites.

$\mathrm{Li}$ and Ragauskas reported the utilization of oxypropylated kraft lignin for target application as rigid foams [10]. In this modification, the oxypropylation process effectively increased the aliphatic $\mathrm{OH}$ content in the lignin by 3.5-fold, as compared to unmodified kraft lignin. For comparison, control PU foams using industry standard Pus (sucrose polyol or glycerol polyol with MDI crosslinkers) were prepared under identical conditions. A methodical approach was undertaken in which sucrose polyol was replaced with increasing fractions of the oxypropylated lignin. The NCO:OH ratio was held constant at 1.7 for these foams. The beginning of the foam reaction is referred to as the cream time, a point at which the reaction mixture turbidity increases as a result of the formation of gas bubbles giving the mixture a creamy consistency and appearance. A shorter cream formation time is generally desirable. In this work, the cream time decreased with increasing lignin content. Impressively, the yield strength and the compressive modulus of lignin PU foams were improved by 1.44 -fold and $135 \%$, respectively, compared to the sucrose polyol PU foams.

Applications of polyurethanes extend beyond adhesives, coatings and structural foams. The polar urethane functional groups and relative chemical inertness makes polyurethanes attractive components of polar stationary phases for chromatographic and chemoselective membrane applications. One effort to leverage lignin for such applications was undertaken by Evtuguin et al. in 2011 [24]. This work employed eucalyptus kraft lignin modified with chain extenders to prepare PU in the presence of carbon nanotubes. The lignin used was modified via oxidative treatment under aerobic conditions and the isocyanate crosslinker was pre-modified with poly (propylene glycol) having terminal TDI groups. 
One of the major objectives of this modification was to ensure that all of the material is covalently bound in the matrix to minimize leaching of small molecular material from composite membranes. The poly (propylene glycol) segments also contribute to very low $\mathrm{Tg}$ values, which made it feasible to fabricate self-plasticizing membranes at room temperature. To maintain the thermoset properties, the polymer had to be synthesized with a NCO:OH ratio of 1.5 and a relatively low $10 \mathrm{wt} . \%$ lignin content. The resultant optimized lignin PU-doped multiwall carbon nanotubes proved moderately effective as ion-selective membranes.

As the efforts discussed in this section suggest, lignin can be used as a promising substitute for petroleum-derived commercial polyols in polyurethane. Some of these studies have already shown the potential use of lignin as the sole hydroxyl group-bearing component. Lignin plays a role as a heterogeneous polyol compound, having both aliphatic and aromatic - $\mathrm{OH}$ groups to react with isocyanates. Urethane bridges are likely to be formed with aliphatic $\mathrm{OH}$ groups over the phenolic groups, yet the presence of phenolic moieties enhances the overall mechanical strength of PU.

Despite the promise of lignin in this area, the uniform reactivity of lignin towards isocyanate is diminished due to the low accessibility of -OH groups, so more studies on pretreatment of lignin to improve the accessibility of reactive sites are needed. When some reaction sites are inaccessible, a higher $\mathrm{NCO}: \mathrm{OH}$ ratio has to be used to attain the target materials. Utilizing low molecular weight lignin with different modifications, such as liquefaction, oxypropylation, demethylation, and hydrogenolysis have all been proven useful for alleviating the need to use an excess of the toxic isocyanates. In addition to the environmental and sustainability considerations, one of the major benefits of using lignin-based PU is to minimize the cost of the overall manufacturing process over current commercial Pus. Thus, a cost analysis on each modification method needs to be undertaken to compare and analyze the profitability of replacing petrochemicals with lignin.

\section{Lignin in Phenol-Formaldehyde (PF) Resins}

Phenol-formaldehyde (PF) resins were synthesized by using condensation of formaldehyde with phenol. PF resins are frequently used as adhesive in wood composites such as particle board or as binders in lamellar wood products like plywood. PF resins are preferred over urea- or other formaldehyde-based resins owing to higher strength, good chemical resistance, dimensional stability and resistance to moisture [25]. The barrier to more widespread use of the superior PF resins is the high cost of petroleum-derived precursors. Lignin has great potential for replacement of the high cost phenolic components of PF resins. In contrast to current works on polyurethanes, which has employed wood-derived lignin, most lignin used in PF resin derives from annual, grassy plants [26,27]. Lignin from these species are high in $p$-coumaryl alcohol units, the least-substituted monolignol unit. Resins made using unmodified lignin always required longer pressing time and high pressing temperatures. It was estimated that kraft lignin has only $10 \%$ of the reactivity towards formaldehyde that phenol has $[26,28]$. Hence, the current trend is to use modified lignin to increase the reactivity towards formaldehyde, a direction discussed for lignin Pus in the previous section. Among all the modifying techniques, the demethylation, phenolation, and hydroxymethylation techniques have emerged as the most effective approaches in the last decade [28]. Generally, formaldehyde reacts with the 2-,4-, and 6position of phenol due to the directing ability of the hydroxyl group for electrophilic substitution. The demethylation converts some of the lignin methoxy groups into hydroxyl groups, resulting in catechol moieties that have increased reactivity with formaldehyde. In hydroxymethylation and phenolation lignin is pretreated with formaldehyde or thermally pretreated with phenols, respectively (Scheme 3). The phenolation procedure involves treating lignin with phenol under acidic conditions in organic solvents, leading to the condensation of phenol with lignin side chains and aromatic rings [29]. 
a)

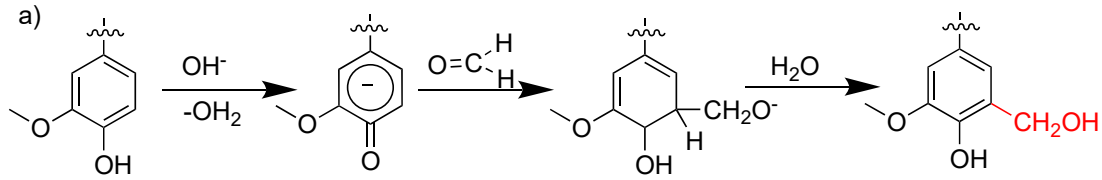

b)

i)<smiles>COc1cc(Cc2ccc(O)cc2)c(C)cc1O</smiles>

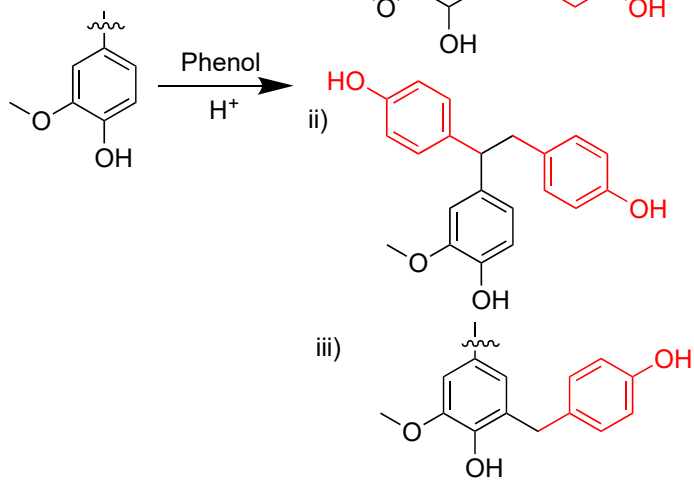

Scheme 3. Generalized scheme to show the modification of lignin via (a) hydroxymethylation and (b) phenolation.

Çetin and Özmen reported lignin-based phenol-formaldehyde films (LPF) that have mechanical properties on par with those of commercial PF resins. The organosolve lignin precursor was hydroxymethylated by its reaction with formaldehyde in alkaline aqueous methanol [30]. The LPF films made in this fashion comprise up to $30 \mathrm{wt}$ \% lignin. Particle board fabrications made using this LPF exhibited a $32 \%$ increase in ultimate tensile strength versus boards prepared using a commercial PF resin. Other physical properties including modulus of rupture, internal board strength, and modulus of elasticity are also comparable. LPF resins further demonstrated lower water absorption than the commercial resin. However, when the lignin content was increased to $>30 \mathrm{wt}$. \%, poor internal board strength perpendicular to the plane of the board was noted. Likewise, the thickness swelling rate of high lignin-content LPF-bonded particleboards $(<0.24 \% \mathrm{~h}-1)$ is higher than that of commercial resin $(0.068 \% \mathrm{~h}-1)$ after $24 \mathrm{~h}$. This may be due to high water uptake ability of the hemicellulose fraction embedded in this type of lignin. A drawback for LPF resins in this study is that they require up to 30-min gelation time. Economical manufacturing of commercial board products, however, requires a gelation time of $10 \mathrm{~min}$ or less [25].

The free formaldehyde content was also higher for LPFs $(0.21-0.25 \%)$ compared to $0.18 \%$ for control PF. Free formaldehyde is a concern from a health and regulatory compliance standpoint.

Another effort to utilize LPF resins for plywood bonding could incorporate up to 50 wt.\% of unmodified kraft lignin without compromising performance [31]. This study demonstrated that the reactivity of LPF resins towards formaldehyde is lower than petroleum-based PF due to the lack of available sites for polymerization. LPF-bonded products required $10 \mathrm{~min}$ of hot-pressing to reach maximum strength. A cooling phase applied immediately after hot pressing resulted in a $25 \%$ increase in bonding strength between layers. This interesting behavior is likely a result of the thermoplastic behavior of lignin in the thermosetting adhesive system. In contrast to previously discussed systems comprising organosolve lignin, these kraft lignin-derived LPF resins showed distinct variation in mechanical properties based on humidity, even after full curing. Tensile shear strength, for example, falls from $6.0 \mathrm{MPa}$ at $2 \%$ relative humidity to $0.9 \mathrm{MPa}$ at $98 \%$ relative humidity. The significant water uptake and consequent dependence of mechanical strength on relative humidity is likely a result of the increase in hemicellulose content present in kraft lignin compared to the essentially saccharide-free organosolve lignin [32]. Despite problems with humidity, the kraft lignin-derived LPF resins exhibit favorable viscosity, low residual solids content, and low free formaldehyde/phenol content that compare favorably to commercial PF resins for similar target applications. 
Another utilization of modified lignin for plywood-bonding LPF resins was reported by Huang and coworkers employing hydroxymethylated alkaline rice straw lignin [25]. These researchers hypothesized that alkaline lignin may perform better than other types of lignin in bonding because larger molecular fragments of alkaline lignin could allow for more rapid gelation [33]. Resins comprising 35 or $50 \mathrm{wt} . \%$ lignin and formaldehyde: phenol ratios of 1.8 or 2.2 gave the best gelation times of 10.2-10.3 min, with impressively low free formaldehyde content (0.01-0.02 wt.\%). The important physical properties like viscosity, residual solid content, gelation time and free formaldehyde content are all well within the range necessary for commercial application. A thorough mechanical properties analysis is still needed on these materials, however, as no mechanical strength analyses were reported (Scheme 4).

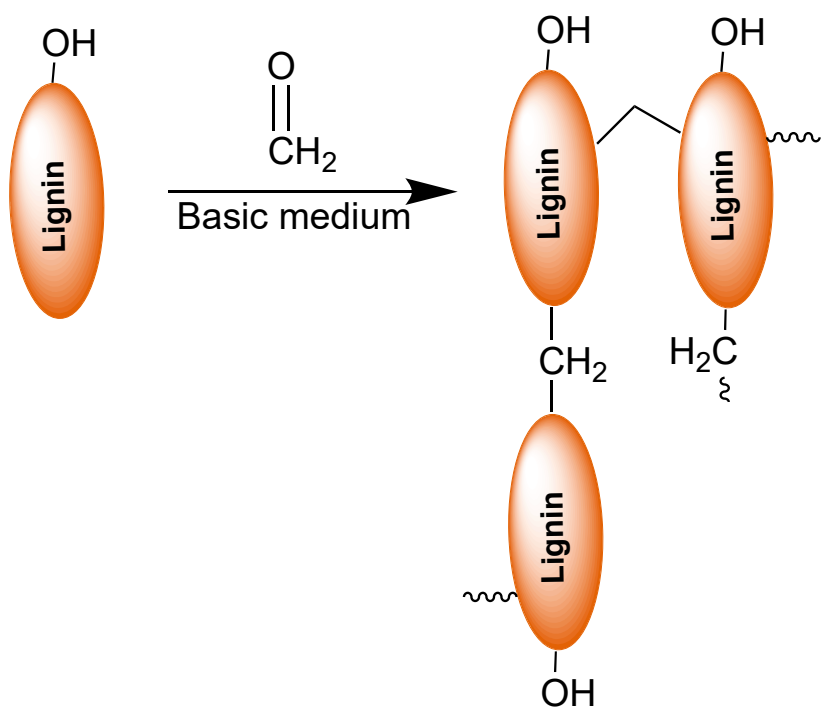

Scheme 4. Generalized scheme for lignin-formaldehyde reaction under basic conditions.

Zhao et al. used phenolated wheat straw steam explosion lignin to prepare LPF resins [34]. The phenolated lignin exhibited a 30\% increase in total phenolic content per gram of material. The resultant LPF resins were used to prepare plywood by using hot-pressing. Plywood bonded with resins in which up to $70 \mathrm{wt} . \%$ of the resin is comprised by lignin passed the Chinese National Standard (GB/T 14732-2006) for first-grade plywood. The best performance in mechanical properties (40 wt.\% lignin and $0.43 \%$ free formaldehyde) were achieved with a plywood having $1.11 \mathrm{MPa}$ of tensile bond strength, compared to $1.15 \mathrm{MPa}$ for traditional commercial PF resin-bonded plywood. The gelation time was only $7 \mathrm{~min}$ and all the other parameters such as viscosity, solid content, and $\mathrm{pH}$ values all are within the parameters required for commercialization standards.

As is the case when preparing lignin PU resins, the utilization of modified lignin resulted in more compatible for PF resin formulations. All the LPF parameters such as viscosity, solid content, free formaldehyde content, and mechanical properties can match those metrics required for commercial resins for plywood. However, the macromolecular structure of lignin limits the number of reactive sites and lowers the number of phenolic moieties per unit mass compared to commercial phenol. These impediments can be minimized through modification techniques. A notable improvement in formaldehyde/phenol mass ratio was observed as increased amount of formaldehyde is required to overcome the steric impediments of phenolic moieties in lignin. As a result, the final free formaldehyde content in LPF resins is stepped up over the commercial PF resins. However, even a small amount of formaldehyde gas can cause serious health problems. Thus, it is required to introduce a standard list of optimal amounts of formaldehyde, specific to each type of modified lignin rather than using an excess. Conversely, Younesi-Kordkheili et al. reported diminishing formaldehyde emission in urea-formaldehyde resin modified with phenolated lignin. Interestingly, even 10\% modified lignin 
incorporation into a resin can lead to a significant decrease in free formaldehyde content $(0.26 \%)$ compared to the control $(0.40 \%)$ [35]. The foregoing examples are summarized in Table 2.

Table 2. Summary of LPF Resins.

\begin{tabular}{lcccccc}
\hline Lignin Type & $\begin{array}{c}\text { Incorporated } \\
\text { Lignin \% of the } \\
\text { Best Sample }\end{array}$ & $\begin{array}{c}\text { Formaldehyde/ } \\
\text { Phenol } \\
\text { Mass Ratio }\end{array}$ & $\begin{array}{c}\text { Free } \\
\text { Formaldehyde } \\
\text { \% }\end{array}$ & $\begin{array}{c}\text { Gelation } \\
\text { Time/Min }\end{array}$ & $\begin{array}{c}\text { Mechanical } \\
\text { Properties/Mpa }\end{array}$ & Ref. \\
\hline $\begin{array}{l}\text { Hydroxymethylated } \\
\text { organosolve lignin }\end{array}$ & 20 & 1.07 & 0.25 & 29 & $\begin{array}{c}\text { Tensile } \\
\text { strength } 1.02\end{array}$ & 31 \\
\hline $\begin{array}{c}\text { Hydroxymethylated } \\
\text { alkaline rice } \\
\text { straw lignin }\end{array}$ & 35 & 1.8 & 0.01 & 10.2 & NA & 26 \\
\hline $\begin{array}{c}\text { Phenolated wheat } \\
\text { straw steam } \\
\text { explosion lignin }\end{array}$ & 40 & 1.5 & 0.43 & 7 & $\begin{array}{c}\text { Tensile } \\
\text { strength } 1.11\end{array}$ & 35 \\
\hline $\begin{array}{c}\text { Unmodified kraft } \\
\text { lignin }\end{array}$ & 50 & NA & 0.40 & 20 & $\begin{array}{c}\text { Lap shear } \\
\text { strength } 3.4\end{array}$ & 32 \\
\hline
\end{tabular}

\section{Lignin-Derived Carbon Fibers}

Carbon fibers (CFs) are light weight and have high tensile strength, specific modulus, low electrical resistivity, and high resistance to torsion, manifesting better mechanical properties than those of steel in many applications for a fraction of the weight [36]. This attractive combination of light weight and high strength have made CFs extremely attractive as components of vehicles to improve fuel efficiency, high-performance sporting goods and as a substitute for infrastructure components. Unfortunately, the high cost of $C F$ precursors has been a hurdle to their more widespread use. The main industrial $C F$ precursors have been polyacrylonitrile (PAN) and pitch [37].

PAN based CFs resulted in higher tensile strength over pitch based fibers, yet pitch based fibers manifested a higher modulus compared to PAN.

Finding more affordable and sustainable CF precursors could lead to a transformative advance in pursuit of high strength materials to replace environmentally damaging petrochemical polymers. Among sustainable CF precursors, lignin has emerged as a premier candidate by merit of its composition by $60 \mathrm{wt} . \%$ carbon, good thermal stability, and the general observation that aromatic polymers tend to more efficiently degrade to CF-type materials than aliphatic precursors do. Lignin based CFs have shown much potential for robust commercial applications, and a plethora of ongoing research can be found in this area over the last 5-10 years. Replacing PAN-derived CF fibers with lignin-derived $\mathrm{CFs}$ would reduce the emission of harmful $\mathrm{CO}_{2}$ by $22 \%$ and could lower manufacturing cost by $30-40 \%$ if preparation could be achieved at similar temperatures. The decrease in the thermoplasticity of lignin, recalcitrance in processing, lower carbon content, low molecular weight fractions, and lower modulus compared to PAN-based fibers has slowed the development of more sustainable lignin-based alternatives [38]. Among many manufacturing processes, this review mainly focusses on low-cost extrusion and melt spinning processes. These methods are convenient and free from using toxic solvents.

Due to diminished thermoplastic and flow properties, the melt spinning of unmodified lignin is a difficult task to accomplish, yet impressive recent attempts have been reported with solvated, unmodified lignin. Baker et al. used both unpurified thiolignin and a sample of the same hardwood thiolignin that was extracted in organic solvents as CF sources [39]. The unpurified lignin exhibited very poor processability under the melt spinning technique, whereas extracted lignin exhibited better spinnability. The extracted lignin consisted of a greater proportion of low molecular weight fractions which are preferentially solubilized in organic solvents. Such low molecular weight fractions have a plasticizing effect on the lignin. The best mechanical properties were achieved when CFs melt spun from extracted lignin were subsequently oxidatively stabilized only at very slow heating rates 
$\left(<0.05^{\circ} \mathrm{C} / \mathrm{min}\right)$. Carbonized fibers produced in this way still did not manifest striking mechanical properties with a tensile strength of $0.51 \mathrm{GPa}$ and tensile modulus of 28.6 GPa.

As the study by Gallego and Baker demonstrates, the recalcitrance of neat lignin and subpar mechanical strength of lignin CFs is a common problem in the field. Significant attempts have been made to employ lignin in polymer blends to achieve CFs having improved processability and strength. In one study, Wang, et al. blended fractionated commercial hardwood thiolignin with poly(lactic acid) (PLA) in varying ratios [40]. After extrusion at $220-240{ }^{\circ} \mathrm{C}$, initial thermal stabilization was accomplished by heating to $280^{\circ} \mathrm{C}$ at a rate of $\left(0.05^{\circ} \mathrm{C} / \mathrm{min}\right)$ followed by carbonization by heating to $1000{ }^{\circ} \mathrm{C}$ at $3{ }^{\circ} \mathrm{C} / \mathrm{min}$. CFs were successfully produced by this method for compositions comprising from $0-20 \mathrm{wt} . \%$ PLA. The addition of PLA results in increased porosity and commensurately lower tensile strength as PLA content increases.

In 2017, Li et al. proposed the use of a miscible blend of fractionated kraft lignin and PAN as a means to increase the processability of $\mathrm{CF}$ formulations [41]. Prior to mixing, kraft lignin was fractionated into water-soluble and insoluble using a common laccase-mediator system. The treatment resulted in fractions having different molecular weights of lignin. It was claimed that treatment also leads to reduced total $\mathrm{OH}$ content groups in both soluble and insoluble fractions, thus improving the interactions with PAN and the nonpolar solvent system. The homogenized blend containing less polydisperse lignin had improved extrusion ability to form CF fibers. To accomplish this desirable blend, target lignin fractions and PAN were blended in a 1:1 weight ratio via electrospinning. Fibers created in this way from the water-insoluble lignin fraction exhibited an impressive elastic modulus of $21.8 \mathrm{GPa}$, on par with that of 20.7 GPa for PAN-based commercial carbon fibers. Water soluble lignin-based CFs had a lower yet still practically viable elastic modulus of $16 \mathrm{GPa}$, similar to the modulus for pure kraft lignin-derived CFs (15.7 GPa). Despite using lignin as a sustainable feedstock in this process, it should be noted that all of the PAN-derived CF reactions emit toxic hydrogen cyanide gas, which is a drawback to this approach [42].

Hosseinaei and coworkers recently reported a creative and intriguing strategy in the area of tuning the processability by blending. In this case, rather than blending lignin with a synthetic polymer, two differently-sourced lignins, hardwood and softwood lignin, were blended. Hardwood lignin consists primarily of 5-substituted syringyl units, so the possibility of aryl crosslinking via dibenzodioxocin linkages is reduced compared to softwood lignin, which contains mostly guaiacyl units [43]. As a result, lower $T g$ values are observed in hardwood lignin, whereas highly branched softwood lignin structure exhibits higher $T g$ values [44]. Due to lower $T g$ values, hardwood lignin shows a promising melt spinning ability, while softwood lignins exhibit more favorable thermostabilizing ability [45]. With these fundamental properties in mind, Housseinaei, et al. mixed organosolve hardwood and soda switchgrass lignin (15-50 wt.\%) in different ratios to investigate the change in mechanical properties of resultant CFs [46]. The lignin mixtures resulted in meltable, miscible blends that could be readily extruded at $180-185^{\circ} \mathrm{C}$. From these materials, it was determined that lower amounts of switchgrass lignin and a very slow heating rate $\left(0.05^{\circ} \mathrm{C} / \mathrm{min}\right)$ provide carbon fibers with the best mechanical properties. Efforts to employ grass-derived lignin in place of softwood lignin led to mixtures that could not be effectively melt spun.

An alternative strategy to blending lignin with other materials is to modify lignin by chemical derivatization prior to processing [47]. Eckert and Abdullah patented the use of acetylated softwood lignin, [48] as a source for CFs. The acetylation process employs acetic anhydride with pyridine as the catalyst at a $50{ }^{\circ} \mathrm{C}$ reaction temperature and is relatively affordable. Acetylated lignin was readily extruded at $220{ }^{\circ} \mathrm{C}$ and stabilized at $240{ }^{\circ} \mathrm{C}$ under a very low heating rate of $0.2{ }^{\circ} \mathrm{C} / \mathrm{min}$, and carbonization occurred at a $4{ }^{\circ} \mathrm{C} / \mathrm{min}$ heating rate to $1150{ }^{\circ} \mathrm{C}$. Although no mechanical data was reported for these initial CFs, Zhang and Ogale have measured the mechanical properties of acetyl lignin-derived CFs by using this procedure with slight modifications [49]. The mechanical properties of these acetyl lignin CFs show significantly improved tensile modulus, tensile strength, and strain-to-failure ( $52 \mathrm{GPa}, 1.04 \mathrm{GPa}$, and $2.0 \%$, respectively) over previously-reported lignin-derived CFs. 
Although lignin-based CFs manifested high feasibility in applying low modulus robust commercial applications, many of the key deficiencies need to be addressed. Already, hardwood lignin is mostly used in melt spinning over softwood due to its higher thermoplastic behavior. Nevertheless, advanced modification of softwood lignin also should be addressed in the future, as considerable amount of biomass is also produced from softwoods. Maintaining the specific conditions of extraction methods to retain more ether linkages ( $\beta-\mathrm{O}-4)$, mask the $\mathrm{OH}$ groups by polymer grafting or copolymerization, or control the polydispersity and molecular weight of lignin fractions may lower the glass transition temperatures of lignin, improving the spinnability. Concurrently, the hemicellulose fraction embedded in lignin may absorb water, causing an increase in void content. Hence, a thorough purification step is required prior to the melt spinning to gain an undamaged, continuous fiber. Addressing these concerns may liberate some of the barrios which prevent lignin-based carbon fibers from achieving their viable use.

\section{Lignin in High Sulfur-Content Materials}

Like lignin, sulfur is one of the major underutilized byproducts of modern industry. Sulfur production, primarily by its removal from petroleum during fuel production, has outpaced demand by up to 7 million tons annually for decades, leading to massive untapped stockpiles for valorization. In 2013, Pyun reported an intriguing method for exploiting this waste sulfur as a component of copolymers by its reaction with olefins via a process called inverse vulcanization [50]. Although elemental sulfur itself is quite brittle, durable materials can be obtained for the copolymers comprising up to $90 \mathrm{wt} . \%$ sulfur [51-54]. These efforts have employed a wide range of starting materials including cellulose, lignin, amino acids, terpenoids, algae acids, polystyrene derivatives, and other olefins [55-70]. More recently, radical-induced aryl halide/sulfur polymerization (RASP) proved similarly effective for preparation of high sulfur-content materials (HSMs) but employing aryl halides in place of the olefins required for inverse vulcanization.

Both inverse vulcanization and RASP have been used to prepare HSMs from elemental sulfur and lignin derivatives. In a 2019 report, the Smith group employed allylated lignin to react via inverse vulcanization with elemental sulfur (Scheme 5A). Allyl lignin reacted with sulfur at $180^{\circ} \mathrm{C}$ in different ratios. Allyl lignin and molten sulfur suffer from significant immiscibility of the two comonomers, thus minimizing the amount of lignin that can be incorporated into the HSM to $5 \mathrm{wt} . \%$. The maximum flexural strength of the allyl lignin HSM was 2.1 MPa, [71] significantly lower than analogous HSMs prepared from functionalized cellulose. Due to the thermal reversibility of S-S bond-formation, however, these materials can be remelted and recast over many cycles without any loss in moduli or strength.

In another report, the RASP process was used to prepare HSMs from chlorolignin and sulfur (Scheme 5B) [72]. Chlorolignin can be obtained either as a byproduct of the bleach paper/pulp industry or prepared from the other lignin sources by using oxidation with aqueous bleach. The sulfur and chlorolignin are fully miscible at the $240{ }^{\circ} \mathrm{C}$ reaction temperature, allowing them to be reacted in any ratio. The study focused on thermoplastic materials, however, so only the remeltable copolymers, comprising up to $20 \mathrm{wt} . \%$ lignin, were studied in detail. The chlorolignin/sulfur HSMs had remarkably improved mechanical strength compared to that of the allylligin/sulfur copolymers. A maximum flexural strength of $>3.6 \mathrm{MPa}$ was achieved for the material comprising $20 \mathrm{wt}$. $\%$ chlorolignin. This flexural strength is on par with that of Portland cement $(3.8 \mathrm{MPa})$, suggesting that these materials could be recyclable cement surrogates. 
A)

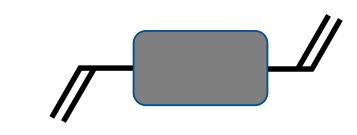

$\mathrm{S}_{8} \stackrel{\Delta}{\longrightarrow} \cdot \mathrm{S}-\mathrm{S}_{\mathrm{n}}-\mathrm{S} \cdot$

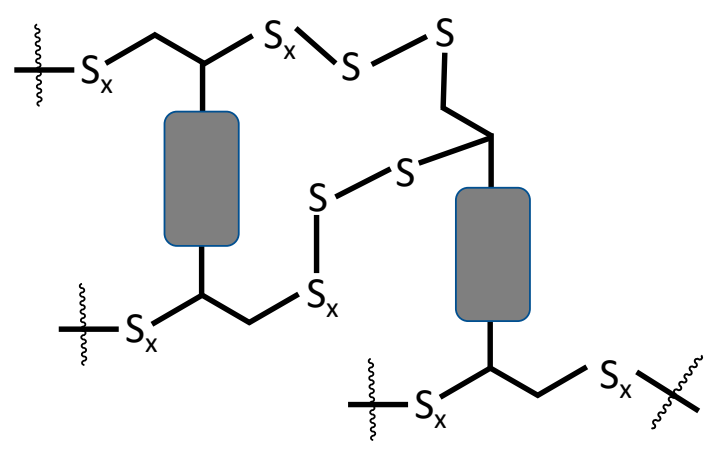

B)

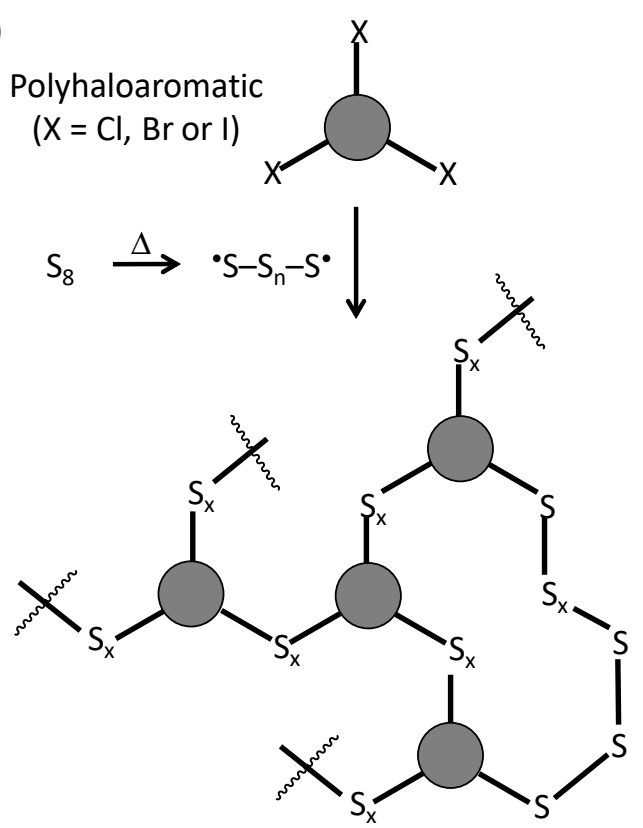

Scheme 5. Established inverse vulcanization of alkenes with majority sulfur (A) and emerging RASP of aryl halide with majority sulfur (B) routes to high sulfur-content materials.

\section{Conclusions}

Although the foregoing review demonstrates some of the promise held by lignin to replace petrochemicals in several important technologies, many challenges remain. One challenge is the complexity of lignin. More efforts must be directed towards the full characterization of lignin from different sources so that firm structure-property relationships can be elucidated. Another area needing more research is in developing more efficient and effective modification protocols to endow lignin with desired properties for each application. Finally, comparing lignin-derived materials to those that have been prepared from purified, discrete small molecular petrochemicals is problematic given the heterogeneous nature of lignin. With recent advances in the production of more well-characterized lignin oils, a potent future direction may be to use these lignin oils, rather than whole lignin, as feedstocks to replace petrochemicals in our emerging sustainable society.

Author Contributions: Author M.S.K. carried out the majority of writing and literature searches associated with this contribution. Author R.C.S. provided funding, editorial and graphic support. All authors have read and agreed to the published version of the manuscript.

Funding: This research was funded by the National Science Foundation of the United States, grant number CHE-1708844.

Conflicts of Interest: The authors declare no conflict of interest.

\section{References}

1. Chakar, F.S.; Ragauskas, A.J. Review of current and future softwood kraft lignin process chemistry. Ind. Crop. Prod. 2004, 20, 131-141. [CrossRef]

2. Tribot, A.; Amer, G.; Alio, M.A.; de Baynast, H.; Delattre, C.; Pons, A.; Mathias, J.-D.; Callois, J.-M.; Vial, C.; Michaud, P. Wood-lignin: Supply, extraction processes and use as bio-based material. Eur. Polym. J. 2019, 112, 228-240. [CrossRef]

3. Doherty, W.O.S.; Mousavioun, P.; Fellows, C.M. Value-adding to cellulosic ethanol: Lignin polymers. Ind. Crop. Prod. 2011, 33, 259-276. [CrossRef]

4. Morandim-Giannetti, A.A.; Agnelli, J.A.M.; Lanças, B.Z.; Magnabosco, R.; Casarin, S.A.; Bettini, S.H.P. Lignin as additive in polypropylene/coir composites: Thermal, mechanical and morphological properties. Carbohydr. Polym. 2012, 87, 2563-2568. [CrossRef] 
5. Zoia, L.; Salanti, A.; Frigerio, P.; Orlandi, M. Exploring allylation and Claisen rearrangement as a novel chemical modification of lignin. BioResources 2014, 9, 6540-6561. [CrossRef]

6. Zakzeski, J.; Bruijnincx, P.C.A.; Jongerius, A.L.; Weckhuysen, B.M. The catalytic valorization of lignin for the production of renewable chemicals. Chem. Rev. 2010, 110, 3552-3599. [CrossRef]

7. Stevens, J.; Gardner, D.J. Enhancing the fuel value of wood pellets with the addition of lignin. Wood Fiber Sci. 2010, 42, 439-443.

8. Wang, Y.-Y.; Cai, C.M.; Ragauskas, A.J. Recent advances in lignin-based polyurethanes. Tappi J. 2017, 16, 1376496. [CrossRef]

9. Mahmood, N.; Yuan, Z.; Schmidt, J.; Xu, C. Depolymerization of lignins and their applications for the preparation of polyols and rigid polyurethane foams: A review. Renew. Sustain. Energy Rev. 2016, 60, 317-329. [CrossRef]

10. Li, Y.; Ragauskas, A.J. Kraft Lignin-Based Rigid Polyurethane Foam. J. Wood Chem. Technol. 2012, 32, $210-224$. [CrossRef]

11. Nacas, A.M.; Ito, N.M.; Sousa, R.R.D.; Spinacé, M.A.; Dos Santos, D.J. Effects of NCO:OH ratio on the mechanical properties and chemical structure of Kraft lignin-based polyurethane adhesive. J. Adhes. 2017, 93, 18-29. [CrossRef]

12. Jia, Z.; Lu, C.; Zhou, P.; Wang, L. Preparation and characterization of high boiling solvent lignin-based polyurethane film with lignin as the only hydroxyl group provider. RSC Adv. 2015, 5, 53949-53955. [CrossRef]

13. Griffini, G.; Passoni, V.; Suriano, R.; Levi, M.; Turri, S. Polyurethane Coatings Based on Chemically Unmodified Fractionated Lignin. ACS Sustain. Chem. Eng. 2015, 3, 1145-1154. [CrossRef]

14. Wu, S.; Zhan, H. Characteristics of demethylated wheat straw soda lignin and its utilization in lignin-based phenolic formaldehyde resins. Cellul. Chem. Technol. 2001, 35, 253-262.

15. Chung, H.; Washburn, N.R. Improved Lignin Polyurethane Properties with Lewis Acid Treatment. ACS Appl. Mater. Interfaces 2012, 4, 2840-2846. [CrossRef]

16. Cateto, C.A.; Barreiro, M.F.; Rodrigues, A.E.; Belgacem, M.N. Optimization Study of Lignin Oxypropylation in View of the Preparation of Polyurethane Rigid Foams. Ind. Eng. Chem. Res. 2009, 48, 2583-2589. [CrossRef]

17. Sadeghifar, H.; Cui, C.; Argyropoulos, D.S. Toward Thermoplastic Lignin Polymers. Part 1. Selective Masking of Phenolic Hydroxyl Groups in Kraft Lignins via Methylation and Oxypropylation Chemistries. Ind. Eng. Chem. Res. 2012, 51, 16713-16720. [CrossRef]

18. Ahvazi, B.; Wojciechowicz, O.; Ton-That, T.-M.; Hawari, J. Preparation of Lignopolyols from Wheat Straw Soda Lignin. J. Agric. Food Chem. 2011, 59, 10505-10516. [CrossRef]

19. Pavier, C.; Gandini, A. Oxypropylation of sugar beet pulp. 2. Separation of the grafted pulp from the propylene oxide homopolymer. Carbohydr. Polym. 2000, 42, 13-17. [CrossRef]

20. Wu, L.C.F.; Glasser, W.G. Engineering plastics from lignin. I. Synthesis of hydroxypropyl lignin. J. Appl. Polym. Sci. 1984, 29, 1111-1123. [CrossRef]

21. Tian, T.; Hu, R.; Tang, B.Z. Room Temperature One-Step Conversion from Elemental Sulfur to Functional Polythioureas through Catalyst-Free Multicomponent Polymerizations. J. Am. Chem. Soc. 2018, 140, 6156-6163. [CrossRef] [PubMed]

22. Pierre, L.E.S.; Price, C.C. The room temperature polymerization of propylene oxide. J. Am. Chem. Soc. 1956, 78, 3432-3436. [CrossRef]

23. Li, Y.; Ragauskas, A.J. Ethanol organosolv lignin-based rigid polyurethane foam reinforced with cellulose nanowhiskers. RSC Adv. 2012, 2, 3347-3351. [CrossRef]

24. Faria, F.A.C.; Evtuguin, D.V.; Rudnitskaya, A.; Gomes, M.T.S.R.; Oliveira, J.A.B.P.; Graca, M.P.F.; Costa, L.C. Lignin-based polyurethane doped with carbon nanotubes for sensor applications. Polym. Int. 2012, 61, 788-794. [CrossRef]

25. El Mansouri, N.E.; Yuan, Q.; Huang, F. Preparation and Characterization of Phenol-Formaldehyde Resins Modified with Alkaline Rice Straw Lignin. Bioresources 2018, 13, 8061-8075. [CrossRef]

26. Pizzi, A.; Cameron, F.-A.; van der Klashorst, G.H. Soda Bagasse Lignin Adhesives for Particleboard. In Adhesives from Renewable Resources; American Chemical Society: Washington, DC, USA, 1989; Volume 385, pp. 82-95.

27. Doherty, W.; Halley, P.; Edye, L.; Rogers, D.; Cardona, F.; Park, Y.; Woo, T. Studies on polymers and composites from lignin and fiber derived from sugar cane. Polym. Adv. Technol. 2007, 18, 673-678. [CrossRef] 
28. Hu, L.; Pan, H.; Zhou, Y.; Zhang, M. Methods to improve lignin's reactivity as a phenol substitute and as replacement for other phenolic compounds: A brief review. Bioresources 2011, 6, 3515-3525.

29. Jiang, X.; Liu, J.; Du, X.; Hu, Z.; Chang, H.-M.; Jameel, H. Phenolation to Improve Lignin Reactivity toward Thermosets Application. ACS Sustain. Chem. Eng. 2018, 6, 5504-5512. [CrossRef]

30. Çetin, N.S.; Özmen, N. Studies on lignin-based adhesives for particleboard panels. Turk. J. Agric. For. 2003, 27, 183-189.

31. Solt, P.; van Herwijnen, H.W.G.; Konnerth, J. Thermoplastic and moisture-dependent behavior of lignin phenol formaldehyde resins. J. Appl. Polym. Sci. 2019, 136, 48011. [CrossRef]

32. Grossman, A.; Vermerris, W. Lignin-based polymers and nanomaterials. Curr. Opin. Biotechnol. 2019, 56, 112-120. [CrossRef] [PubMed]

33. Forss, K.G.; Fuhrmann, A. Finnish plywood, particleboard, and fiberboard made with a lignin-base adhesive. For. Prod. J. 1979, 29, 39-43.

34. Zhao, M.; Jing, J.; Zhu, Y.; Yang, X.; Wang, X.; Wang, Z. Preparation and performance of lignin-phenolformaldehyde adhesives. Int. J. Adhes. Adhes. 2016, 64, 163-167. [CrossRef]

35. Younesi-Kordkheili, H.; Pizzi, A.; Niyatzade, G. Reduction of Formaldehyde Emission from Particleboard by Phenolated Kraft Lignin. J. Adhes. 2016, 92, 485-497. [CrossRef]

36. Kadla, J.F.; Kubo, S.; Venditti, R.A.; Gilbert, R.D.; Compere, A.L.; Griffith, W. Lignin-based carbon fibers for composite fiber applications. Carbon 2002, 40, 2913-2920. [CrossRef]

37. Lim, T.H.; Yeo, S.Y. Investigation of the degradation of pitch-based carbon fibers properties upon insufficient or excess thermal treatment. Sci. Rep. 2017, 7, 4733. [CrossRef] [PubMed]

38. Souto, F.; Calado, V.; Pereira, N. Lignin-based carbon fiber: A current overview. Mater. Res. Express 2018, 5, 072001. [CrossRef]

39. Baker, D.A.; Gallego, N.C.; Baker, F.S. On the characterization and spinning of an organic-purified lignin toward the manufacture of low-cost carbon fiber. J. Appl. Polym. Sci. 2012, 124, 227-234. [CrossRef]

40. Wang, S.; Li, Y.; Xiang, H.; Zhou, Z.; Chang, T.; Zhu, M. Low cost carbon fibers from bio-renewable lignin/poly (lactic acid)(PLA) blends. Compos. Sci. Technol. 2015, 119, 20-25. [CrossRef]

41. Li, Q.; Xie, S.; Serem, W.K.; Naik, M.T.; Liu, L.; Yuan, J.S. Quality carbon fibers from fractionated lignin. Green Chem. 2017, 19, 1628-1634. [CrossRef]

42. Jin, J.; Ding, J.; Klett, A.; Thies, M.C.; Ogale, A.A. Carbon Fibers Derived from Fractionated-Solvated Lignin Precursors for Enhanced Mechanical Performance. ACS Sustain. Chem. Eng. 2018, 6, 14135-14142. [CrossRef]

43. Karhunen, P.; Rummakko, P.; Sipilä, J.; Brunow, G.; Kilpeläinen, I. Dibenzodioxocins; a novel type of linkage in softwood lignins. Tetrahedron Lett. 1995, 36, 169-170. [CrossRef]

44. Brodin, I. Chemical Properties and Thermal Behaviour of Kraft Lignins. Licentiate Thesis, KTH Royal Institute of Technology, Stockholm, Sweden, 2009.

45. Fang, W.; Yang, S.; Wang, X.-L.; Yuan, T.-Q.; Sun, R.-C. Manufacture and application of lignin-based carbon fibers (LCFs) and lignin-based carbon nanofibers (LCNFs). Green Chem. 2017, 19, 1794-1827. [CrossRef]

46. Hosseinaei, O.; Harper, D.P.; Bozell, J.J.; Rials, T.G. Improving Processing and Performance of Pure Lignin Carbon Fibers through Hardwood and Herbaceous Lignin Blends. Int. J. Mol. Sci. 2017, 18, 1410. [CrossRef]

47. Akpan, E.I. Stabilization of Lignin Fibers. In Sustainable Lignin for Carbon Fibers: Principles, Techniques, and Applications; Springer: Berlin/Heidelberg, Germany, 2019; pp. 325-352.

48. Eckert, R.C.; Abdullah, Z. Carbon Fibers from Kraft Softwood Lignin. U.S. Patent 20080317661, 25 December 2008.

49. Zhang, M.; Ogale, A. Carbon fibers from dry-spinning of acetylated softwood kraft lignin. Carbon 2014, 69, 626-629. [CrossRef]

50. Chung, W.J.; Griebel, J.J.; Kim, E.T.; Yoon, H.; Simmonds, A.G.; Ji, H.J.; Dirlam, P.T.; Glass, R.S.; Wie, J.J.; Nguyen, N.A.; et al. The use of elemental sulfur as an alternative feedstock for polymeric materials. Nat. Chem. 2013, 5, 518-524. [CrossRef]

51. Griebel, J.J.; Glass, R.S.; Char, K.; Pyun, J. Polymerizations with elemental sulfur: A novel route to high sulfur content polymers for sustainability, energy and defense. Prog. Polym. Sci. 2016, 58, 90-125. [CrossRef]

52. Griebel, J.J.; Li, G.; Glass, R.S.; Char, K.; Pyun, J. Kilogram scale inverse vulcanization of elemental sulfur to prepare high capacity polymer electrodes for Li-S batteries. J. Polym. Sci. Part A Polym. Chem. 2015, 53, 173-177. [CrossRef] 
53. Westerman, C.R.; Jenkins, C.L. Dynamic Sulfur Bonds Initiate Polymerization of Vinyl and Allyl Ethers at Mild Temperatures. Macromolecules 2018, 51, 7233-7238. [CrossRef]

54. Griebel, J.J.; Namnabat, S.; Kim, E.T.; Himmelhuber, R.; Moronta, D.H.; Chung, W.J.; Simmonds, A.G.; Kim, K.-J.; van der Laan, J.; Nguyen, N.A.; et al. New Infrared Transmitting Material via Inverse Vulcanization of Elemental Sulfur to Prepare High Refractive Index Polymers. Adv. Mater. 2014, 26, 3014-3018. [CrossRef]

55. Parker, D.J.; Jones, H.A.; Petcher, S.; Cervini, L.; Griffin, J.M.; Akhtar, R.; Hasell, T. Low cost and renewable sulfur-polymers by inverse vulcanization, and their potential for mercury capture. J. Mater. Chem. A Mater. Energy Sustain. 2017, 5, 11682-11692. [CrossRef]

56. Hasell, T.; Smith Jessica, A.; Green Sarah, J.; Petcher, S.; Parker Douglas, J.; Zhang, B.; Wu, X.; Kelly Catherine, A.; Baker, T.; Jenkins Mike, J.; et al. Crosslinker co-polymerisation for property control in inverse vulcanisation. Chemistry 2019. [CrossRef]

57. Mann, M.; Kruger, J.E.; Andari, F.; McErlean, J.; Gascooke, J.R.; Smith, J.A.; Worthington, M.J.H.; McKinley, C.C.C.; Campbell, J.A.; Lewis, D.A.; et al. Sulfur polymer composites as controlled-release fertilizers. Org. Biomol. Chem. 2019, 17, 1929-1936. [CrossRef] [PubMed]

58. Lundquist, N.A.; Worthington, M.J.H.; Adamson, N.; Gibson, C.T.; Johnston, M.R.; Ellis, A.V.; Chalker, J.M. Polysulfides made from re-purposed waste are sustainable materials for removing iron from water. RSC Adv. 2018, 8, 1232-1236. [CrossRef]

59. Hoefling, A.; Lee, Y.J.; Theato, P. Sulfur-Based Polymer Composites from Vegetable Oils and Elemental Sulfur: A Sustainable Active Material for Li-S Batteries. Macromol. Chem. Phys. 2017, 218, 1600303. [CrossRef]

60. Qin, X.; He, Y.; Khan, S.; Zhang, B.; Chen, F.; Dong, D.; Wang, Z.; Zhang, L. Controllable Synthesis and Characterization of Soybean-Oil-Based Hyperbranched Polymers via One-Pot Method. ACS Sustain. Chem. Eng. 2018, 6, 12865-12871. [CrossRef]

61. Valle, S.F.; Giroto, A.S.; Klaic, R.; Guimaraes, G.G.F.; Ribeiro, C. Sulfur fertilizer based on inverse vulcanization process with soybean oil. Polym. Degrad. Stab. 2019, 162, 102-105. [CrossRef]

62. Worthington, M.J.H.; Shearer, C.J.; Esdaile, L.J.; Campbell, J.A.; Gibson, C.T.; Legg, S.K.; Yin, Y.; Lundquist, N.A.; Gascooke, J.R.; Albuquerque, I.S.; et al. Sustainable Polysulfides for Oil Spill Remediation: Repurposing Industrial Waste for Environmental Benefit. Adv. Sustain. Syst. 2018, 2, 1800024. [CrossRef]

63. Worthington, M.J.H.; Kucera, R.L.; Albuquerque, I.S.; Gibson, C.T.; Sibley, A.; Slattery, A.D.; Campbell, J.A.; Alboaiji, S.F.K.; Muller, K.A.; Young, J.; et al. Laying Waste to Mercury: Inexpensive Sorbents Made from Sulfur and Recycled Cooking Oils. Chem. Eur. J. 2017, 23, 16219-16230. [CrossRef]

64. Crockett, M.P.; Evans, A.M.; Worthington, M.J.H.; Albuquerque, I.S.; Slattery, A.D.; Gibson, C.T.; Campbell, J.A.; Lewis, D.A.; Bernardes, G.J.L.; Chalker, J.M. Sulfur-Limonene Polysulfide: A Material Synthesized Entirely from Industrial By-Products and Its Use in Removing Toxic Metals from Water and Soil. Angew. Chem. Int. Ed. 2016, 55, 1714-1718. [CrossRef]

65. Fu, C.; Li, G.; Zhang, J.; Cornejo, B.; Piao, S.S.; Bozhilov, K.N.; Haddon, R.C.; Guo, J. Electrochemical Lithiation of Covalently Bonded Sulfur in Vulcanized Polyisoprene. ACS Energy Lett. 2016, 1, 115-120. [CrossRef]

66. Hoefling, A.; Nguyen, D.T.; Lee, Y.J.; Song, S.-W.; Theato, P. A sulfur-eugenol allyl ether copolymer: A material synthesized via inverse vulcanization from renewable resources and its application in Li-S batteries. Mater. Chem. Front. 2017, 1, 1818-1822. [CrossRef]

67. Thiounn, T.; Tennyson, A.G.; Smith, R.C. Durable, Acid-Resistant Copolymers from Industrial By-Product Sulfur and Microbially-Produced Tyrosine. RSC Adv. 2019, 9, 31460-31465. [CrossRef]

68. Smith, A.D.; Thiounn, T.; Lyles, E.W.; Kibler, E.K.; Smith, R.C.; Tennyson, A.G. Combining Agriculture and Energy Industry Waste Products to Yield Recyclable, Thermally Healable Copolymers of Elemental Sulfur and Oleic Acid. J. Polym. Sci. Part A 2019, 57, 1704-1710. [CrossRef]

69. Lauer, M.K.; Estrada-Mendoza, T.A.; McMillen, C.D.; Chumanov, G.; Tennyson, A.G.; Smith, R.C. Durable, Remeltable Materials from Agricultural and Petrochemical Wastes. Adv. Sustain. Syst. 2019. [CrossRef]

70. Thiounn, T.; Lauer, M.K.; Bedford, M.S.; Smith, R.C.; Tennyson, A.G. Thermally-Healable Network Solids of Sulfur-Crosslinked Poly(4-allyloxystyrene). RCS Adv. 2018, 8, 39074-39082. [CrossRef] 
71. Karunarathna, M.; Lauer, M.K.; Thiounn, T.; Smith, R.C.; Tennyson, A.G. Valorisation of Waste to Yield Recyclable Composites of Elemental Sulfur and Lignin. J. Mater. Chem. A 2019, 7, 15683-15690. [CrossRef]

72. Karunarathna, M.; Tennyson, A.G.; Smith, R.C. Facile New Approach to High Sulfur-Content Materials and Preparation of Sulfur-Lignin Copolymers. J. Mater. Chem. A 2019, 8, 548-553. [CrossRef]

(C) 2020 by the authors. Licensee MDPI, Basel, Switzerland. This article is an open access article distributed under the terms and conditions of the Creative Commons Attribution (CC BY) license (http://creativecommons.org/licenses/by/4.0/). 